\title{
INFRAESTRUCTURAS URBANAS Y MODERNIDAD. MADRID, NUEVAS NECESIDADES Y NUEVOS SERVICIOS DE UNA METRÓPOLI MODERNA, 1900-1936
}

\author{
URBAN INFRASTRUCTURES AND MODERNITY. MADRID, NEW NEEDS \\ AND PUBLIC SERVICES OF A MODERN METROPOLIS, 1900-1936
}

\author{
Luis Enrique Otero Carvajal*1, Nuria Rodríguez-Martín ${ }^{2}$ \\ ${ }^{1}$ Universidad Complutense de Madrid, España \\ ${ }^{2}$ Universidad del País Vasco/Euskal Herriko Unibertsitatea, Bilbao, España
}

\begin{abstract}
RESUMEN: En el último tercio del siglo XIX el crecimiento demográfico y la expansión urbana agravaron los problemas de hacinamiento y salubridad en las grandes urbes europeas. La nueva sociedad urbana demandó el desarrollo de las infraestructuras y los servicios públicos. Sin redes de abastecimiento de agua y alimentación, sin sistemas de eliminación y tratamiento de residuos - sólidos y líquidos - , sin una red de salud pública que solventara los problemas de salubridad y sanitarios, sin nuevos sistemas de transporte que permitieran la movilidad interior de las metrópolis en construcción, la sociedad urbana de comienzos del siglo xx hubiera colapsado, incapaz de hacer frente a los retos de su expansión acelerada. En España este proceso se desarrolló durante el primer tercio del siglo Xx, el crecimiento urbano fue acompañado por la mejora de las infraestructuras y la expansión de los sistemas de transporte público y privado, en los años treinta la sociedad urbana española, con Madrid y Barcelona a la cabeza, lideraba la gran transformación que acercaba al país a la modernidad y a los parámetros de las modernas sociedades europeas.
\end{abstract}

PALABRAS CLAVE: Madrid, infraestructuras, servicios municipales, electricidad, redes de transporte, abastecimiento de agua, alcantarillado, recogida y eliminación de residuos.

ABSTRACT: Dramatic urban growth in the late $19^{\text {th }}$ Century exacerbated overcrowding and sanitation and health problems experienced by most of the largest European cities at the time. The new urban society required infrastructures and public services. Unable to cope with challenges of rapid urban expansion, cities would have been collapsed at the early $20^{\text {th }}$ Century if not for improvements in infrastructures and in public and municipal services, such as water supply and sewage systems, refuse collection and disposal, health services and urban transport systems. These processes took place in Spain during the first third of the $20^{\text {th }}$ Century, where urban growth was accompanied by improvements in infrastructures and by the expansion of public and private transport systems. In the thirties, Spanish urban society, whit Madrid and Barcelona at the forefront, led the great transformation that brought the country closer to Modernity and to the parameters of modern European societies.

KEY WORDS: Madrid, infrastructures, municipal services, electricity, transportation network, water supply, sewage system, refuses collection and disposal.

* Correspondencia a: Luis Enrique Otero Carvajal. Departamento de Historia Moderna e Historia Contemporánea. Planta 10, despacho 13. Facultad de Geografía e Historia. Universidad Complutense de Madrid. c/ Profesor Aranguren s/n. Ciudad Universitaria. Madrid 28040 - leotero@ucm.es - https://orcid.org/0000-0002-2492-238X

Cómo citar: Otero Carvajal, Luis Enrique; Rodríguez-Martín, Nuria (2019). «Infraestructuras urbanas y Modernidad. Madrid, nuevas necesidades y nuevos servicios de una metrópoli moderna, 1900-1936»; Historia Contemporánea, 59, 21-57. (https://doi.org/10.1387/hc.18522).

Recibido: 13 noviembre, 2017; aceptado: 17 abril, 2018.

ISSN 1130-2402 - elSSN 2340-0277 / (C) 2019 UPV/EHU

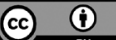


El crecimiento demográfico y la expansión urbana del último tercio del siglo XIX agravó los problemas de hacinamiento y salubridad en las grandes urbes europeas, la nueva sociedad urbana demandó el desarrollo de las infraestructuras y los servicios públicos. Sin redes de abastecimiento de agua y alimentación, sin sistemas de eliminación y tratamiento de residuos - sólidos y líquidos - , sin una red de salud pública que enfrentara los problemas de salubridad y sanitarios, sin nuevos sistemas de transporte que permitieran la movilidad interior de las metrópolis en construcción, la sociedad urbana de comienzos del siglo xx hubiera colapsado, incapaz de hacer frente a los retos de su expansión acelerada.

Ciudades más grandes, extensas y pobladas transformaron la economía urbana. Un foco de problemas y preocupaciones para las autoridades municipales y estatales, pero también de oportunidades para la aparición y consolidación de nuevos negocios, de nuevas industrias y mercados laborales, que emplearon a miles de personas conforme los nuevos servicios públicos de transportes, comunicaciones, infraestructuras se expandían para hacer posible la moderna vida urbana.

Entre 1900 y 1936 la sociedad española experimentó un intenso proceso de cambio liderado por la sociedad urbana. Crecimiento demográfico, intensificación de los procesos migratorios del campo a las ciudades, reducción de las tasas de analfabetismo, expansión de la segunda industrialización, transformación de los mercados laborales, terciarización, consolidación de los partidos y sindicatos de masas, elevación de los niveles de vida, primera irrupción de la sociedad de consumo, nuevos hábitos y estilos de vida fueron algunos de los indicadores de la gran transformación que, con cierto retraso respecto a otras sociedades europeas, registró España durante el primer tercio del siglo $\mathrm{XX}^{1}$.

\section{Madrid, una moderna metrópoli europea}

Madrid se convirtió en el primer tercio del siglo Xx en una ciudad de ciudades. La expansión del espacio urbano, mediante la incorporación del extrarradio y los pueblos colindantes, puso en marcha el proceso de metropolización de la capital española. Como Londres, París o Berlín, Ma-

${ }^{1}$ Beascoechea Gangoiti y Otero Carvajal (eds.), 2015; Otero Carvajal y Pallol Trigueros (eds.), 2017; Otero Carvajal y Pallol Trigueros (eds.), 2018; Martínez Martín y Otero Carvajal (eds.), 2018; Otero Carvajal y De Miguel Salanova (eds.), 2018. 
drid articuló diversos núcleos de población, mediante la construcción de una red de transporte integrada, con la combinación de ferrocarril, tranvía, Metro, autobuses y automóviles ${ }^{2}$.

Inmigración en continuo aumento y crecimiento vegetativo al fin positivo se aliaron para multiplicar el número de habitantes de la capital. El aumento demográfico exigió la extensión urbana. Madrid se convirtió en una metrópoli por el número de sus habitantes y por su cada vez mayor extensión urbana. Aunque la era de su Ensanche aún no había terminado, a partir de 1900 el futuro de Madrid comenzó a jugarse mucho más allá de su término municipal ${ }^{3}$. En el extrarradio surgieron nuevas barriadas, mal y modestamente construidas, destino de las familias trabajadoras. Tetuán de las Victorias, Bellas Vistas, Prosperidad o La Guindalera alcanzaron los 20.000 habitantes, tantos como los de una capital de provincias ${ }^{4}$.

También comenzaron a experimentar explosivos aumentos de población los pueblos colindantes, como Chamartín de la Rosa, Vicálvaro, Vallecas o los Carabancheles. Viejos pueblos hasta entonces adormecidos a la sombra de la capital, cayeron en su campo de gravedad y fueron perdiendo su perfil rural a medida que desempeñaban funciones subsidiarias para la capital que los devoraba.

\section{Agua para todos}

La expansión urbana sólo fue posible por la mejora y desarrollo de las infraestructuras, como ya se había puesto de manifiesto a mediados del siglo XIX con la construcción del Canal de Isabel II, inaugurado el 28 de junio de $1858^{5}$.

Durante el primer tercio del siglo Xx, el abastecimiento de agua potable a Madrid lo realizaban el Ayuntamiento, a través de los denominados «antiguos viajes» o «viajes de agua» - una red de canalizaciones de aguas subterráneas a fuentes públicas de propiedad municipal-, la So-

2 Otero Carvajal, 2013 y 2017.

3 Otero Carvajal, 2007 y 2014, Rodríguez Martín, 2015; Pallol Trigueros, 2015; Vicente Albarrán, 2015; Carballo Barral, 2015; Díaz Simón, 2016; De Miguel Salanova, 2016.

4 Vorms, 2012; Pallol, Vicente y Hernández, 2017.

5 Matés-Barco, 2013; Matés-Barco y Novo López, 2017. 
ciedad Hidráulica Santillana ${ }^{6}$, y el Canal de Isabel II, que suministraba alrededor del $90 \%$ del agua consumida en la ciudad. El Canal comprendía todo un conjunto de obras e instalaciones (presas, embalses, acueductos, depósitos, acequias, el canal propiamente dicho, una red de distribución y de alcantarillado...) propiedad del Estado ${ }^{7}$. A comienzos del siglo XX, la obsolescencia de gran parte de sus infraestructuras y el aumento exponencial del consumo y de la demanda de agua limpia, consecuencia del crecimiento urbano y demográfico, colocaron al Canal en una situación insostenible. Las mayores dificultades las planteaba la limitada red de distribución, que no alcanzaba a los nuevos barrios que se habían construido en el Ensanche y el extrarradio. A este problema se unía la orografía de la ciudad, pues una parte de los barrios construidos durante el último tercio del siglo XIX estaban situados a mayor altura que los depósitos existentes, por lo que resultaba imprescindible construir depósitos elevados y centrales elevadoras de agua ${ }^{8}$. En 1903, Emilio Loza Collado, médico de la Beneficencia municipal, señalaba que $\$ 200.000$ habitantes y 4.000 edificios carecen [...] de un abastecimiento regular, y más del 50 por 100 del agua suministrada se desperdicia lastimosamente» ${ }^{9}$. El propio Canal reconocía los problemas de distribución, y se mostraba comprensivo con el descontento y las protestas de la población ${ }^{10}$.

La solución pasaba por realizar grandes inversiones para actualizar y ampliar la red. En 1907 se formuló y presupuestó un ambicioso plan de obras por valor de 36 millones de pesetas, con el objeto de aumentar el volumen de agua conducida a Madrid y mejorar su distribución en el interior de la ciudad. El plazo de ejecución previsto para finales de 1912 tuvo que ser prorrogado hasta 1922, por la insuficiencia de recursos del Canal y el aumento de sus obligaciones por el crecimiento de la población de Ma-

${ }^{6}$ La Sociedad Hidráulica Santillana constituida en 1905 para explotar una concesión obtenida por RO de 17 de abril de 1900 para surtir de agua procedente del río Manzanares a los barrios situados en las zonas altas de Madrid. Ayuntamiento de Madrid, 1910. Villanueva Larraya, 1995, Sanz García, 1990.

7 Los primeros cien años del Canal de Isabel II, 1954; Rueda Laffond, 1994. Espinosa Romero y González Reglero (coord.), 2001; Martínez Vázquez de Parga, 2001.

${ }^{8}$ Cuando se construyó el Canal de Isabel II los depósitos de agua se situaron a una altura de 680 metros sobre el nivel del mar, al estar Madrid a una altitud máxima de $670 \mathrm{~m}$. los nuevos barrios tras la aprobación del Plan de Ensanche, como el de Chamberí, Pozas, Vallehermoso, Salamanca, etc., estaban a una altura de 670 a $710 \mathrm{~m}$.

${ }^{9}$ Loza y Collado, 1903, p. 65.

${ }^{10}$ Canal de Isabel II, 1909, pp. 50-51. 
drid. Al comenzar los años veinte quedaban trabajos y proyectos sin ejecutar, que se vieron agravados por el conflicto con la Sociedad Hidráulica Santillana, que desde 1912 ostentaba el servicio de distribución de agua a la zona alta de Madrid. En 1925 Julián Besteiro denunciaba que «sin derecho alguno, una Empresa particular está exponiendo a Madrid a peligros que no se atrevería a provocar el más desenfrenado terrorista» ${ }^{11}$. La suspensión de las obras se prolongó hasta 1928, cuando los tribunales desestimaron las reclamaciones de Santillana, y el Canal de Isabel II pudo abordar sin cortapisas los trabajos de ampliación de los embalses, depósitos y mejora y extensión de su red de distribución ${ }^{12}$. Se retomaron las obras del cuarto depósito de agua, en el municipio de Chamartín de la Rosa, y la ampliación de la red distribuidora, se instalaron 42.310 metros de tuberías en 1930 y 13.817 en 1931. En 1935, comenzaron las obras de los depósitos quinto y sexto, así como otras importantes operaciones relacionadas con la mejora de infraestructuras ${ }^{13}$.

La ampliación y mejora de la red de suministro fue acompañada de la racionalización de los sistemas de distribución. Se suprimió la venta de agua a caño libre, sustituida por el sistema de aforo o el de contador, que el Canal trató de implantar para todos sus abonados, a pesar de las protestas por el posible encarecimiento de las tarifas ${ }^{14}$, justificado por la necesidad de evitar el despilfarro de agua, dado el aumento del consumo y del número de abonados. A finales de los años veinte, el abastecimiento diario de agua a Madrid se acercaba a los $303.000 \mathrm{~m}^{3}$, de los que la mayor parte correspondían al Canal ${ }^{15}$. La institución calculaba en 1928 la disponibilidad de 300 litros de agua diarios por habitante, y un consumo de 288 litros por habitante y día, en una población que superaba los 800.000 vecinos. El agua para consumo doméstico suministrada por contador $^{16}$ se tarifaba a 30 céntimos el primer $\mathrm{m}^{3}$, a partir del segundo $\mathrm{m}^{3}$ la tarifa se reducía progresivamente (tabla 1). El coste era inferior para los

11 Besteiro, 1925.

12 RO de 2 de abril de 1928, publicada en Gaceta de Madrid de 3 de abril de 1928.

13 Decreto de 21 de agosto de 1934, publicado en Gaceta de Madrid de 22 de agosto de 1934.

14 Heraldo de Madrid, 15 de enero de 1909.

15 El Canal transportaba a Madrid diariamente $233.000 \mathrm{~m}^{3}$ de agua en 1929 e Hidráulica Santillana entre 40.000 y $60.000 \mathrm{~m}^{3}$ diarios. Ayuntamiento de Madrid, s.f. [¿1929?], p. 114.

${ }^{16}$ El agua suministrada por aforo era un $20 \%$ más cara respecto a la suministrada por contador. 
edificios con los alquileres más bajos, por lo que se favorecía a las familias con menores ingresos ${ }^{17}$. El mayor consumidor de agua era el Ayuntamiento, que gastaba el 31,2\% del total de la conducida a Madrid por el Canal $^{18}$, suministrada de forma gratuita para atender los establecimientos benéficos, dependencias municipales y servicios públicos, como el de incendios, mercados, mataderos, limpieza y riego de calles, parques, jardines y alcantarillado, fuentes públicas y monumentales, casas de socorro, urinarios y retretes públicos ${ }^{19}$.

\section{Tabla 1}

Abonados al Canal de Isabel II entre 1903 y 1935, clasificados por sistemas de suministro

\begin{tabular}{lrrrrrr}
\hline \multicolumn{1}{c}{ Tipo de concesión } & 1903 & 1916 & 1920 & 1925 & 1930 & \multicolumn{1}{c}{1935} \\
\hline Caño libre & 6.315 & 695 & 353 & 149 & 1 & 1 \\
Por aforo & 1.700 & 1.351 & 1.251 & 1.404 & 1.413 & 1.352 \\
Por contador & 2.509 & 11.239 & 12.590 & 16.107 & 22.410 & 27.625 \\
\hline Total concesiones & 10.524 & 13.285 & 14.194 & 17.660 & 23.824 & 28.977 \\
\hline
\end{tabular}

Fuente: Memorias del Canal de Isabel II, distintos años, elaboración propia.

Los nuevos hábitos de higiene y de consumo, con la extensión entre las clases pudientes de la higiene personal y del baño elevaron las exigencias respecto al abastecimiento y la calidad del agua. Un fenómeno que en el primer tercio del siglo XX no dejo de crecer en Madrid, con la aparición

${ }^{17}$ Las viviendas con alquileres entre 250 y 500 pesetas anuales pagaban a 0,07 pesetas el m3, y 0,05 pesetas las viviendas con alquileres por debajo de las 250 pesetas anuales. Durante el primer tercio del siglo xx el agua corriente suministrada por el Canal de Isabel II estaba adscrita a las fincas, lo habitual era que los inquilinos la abonaran como parte del recibo del alquiler.

${ }^{18}$ Según los cálculos del Canal de Isabel II, el gasto de agua se distribuía de la siguiente forma: consumo doméstico y Beneficencia, 55,7\%; Ayuntamiento de Madrid, $31,2 \%$; riegos agrícolas, 9,5\%, establecimientos del Estado, 3,6\%. Bello Poëyusan, s.f. [¿1929?], p. XXIX.

${ }^{19}$ El excesivo consumo de agua que según el Canal de Isabel II realizaba el Ayuntamiento fue motivo de constantes fricciones. Archivo General del Canal de Isabel II y Archivo de Villa de Madrid (en adelante AVM) 
de fregaderos, lavabos, bidés, bañeras portátiles, que progresivamente fueron sustituidos por nuevos modelos fijos, unidos a la red de agua corriente en las cocinas y los cuartos de baño de los barrios y edificios conectados a la red de suministro. La llegada del agua corriente a los barrios y hogares se produjo de manera desigual en función de los diferentes niveles de renta y equipamiento de los mismos, debido a las altas inversiones requeridas para la extensión de la red. Un proceso que intensificó la segregación del espacio urbano y social de Madrid puesto en marcha con el Ensanche y la renovación del centro urbano, con la reforma de la Puerta del Sol en la segunda mitad del siglo XIX, y la construcción de la Gran Vía en el primer tercio del siglo XX.

Junto a la red de distribución, la red de evacuación completaba el ciclo del agua. A finales del siglo XIX la red de alcantarillas era limitada, circunscrita a la zona interior de la ciudad. Se encontraba además en muy mal estado, como puso de manifiesto la epidemia de cólera de 1885, que planteó la necesidad de construir una red de alcantarillado digna de tal nombre. El mayor impulso llegó con la ejecución entre 1913 y 1923 del Proyecto General de Saneamiento del Subsuelo de Madrid, prorrogado en años siguientes, que reformó las alcantarillas antiguas y construyó 385 nuevos kilómetros de alcantarillado hasta 1936, y hasta alcanzar los $490 \mathrm{~km}$ de longitud ${ }^{20}$. Las obras se extendieron a gran parte de los nuevos barrios de la ciudad, incluido el extrarradio, aunque no lograron erradicar por completo los pozos negros, que El Imparcial calificaba como «una de las mayores vergüienzas madrileñas» ${ }^{21}$, desde 1922 el Ayuntamiento dejó de conceder autorizaciones para su construcción, permitiendo sólo las fosas sépticas. Todavía en 1929 se contabilizaban en la ciudad 981 pozos negros y 240 fosas sépticas, donde iban a parar las aguas fecales de los edificios que no estaban conectados a la red de alcantarillado, el $72 \%$ se encontraba en los distritos de Inclusa y Latina, dos de los más pobres de la ciudad. La mejora de la red de saneamiento de Madrid se completó con las obras de encauzamiento y saneamiento del río Manzanares entre 1914 y 1926, con participación del Ministerio de Fomento, mediante la construcción de dos grandes colectores y una estación de tratamiento y depuración de aguas fecales, al sur de la ciudad ${ }^{22}$.

20 Pinto Crespo; Gili Ruiz y Velasco Medina, 2015.

21 El Imparcial, 8 de octubre de 1924.

22 Pinto Crespo; Gili Ruiz y Velasco Medina, 2015, pp. 254-263. 


\section{El problema de las basuras}

La limpieza de Madrid era responsabilidad del Servicio Municipal de Limpiezas y comprendía distintos trabajos, siendo los más importantes el barrido y baldeo de vías públicas, la limpieza de alcantarillas y pozos negros, y la recogida, tratamiento y eliminación de desechos sólidos, tarea que los empleados del Consistorio realizaban en colaboración con los traperos. La cuestión de las basuras urbanas, que la prensa del momento acabó por denominar genéricamente «el problema de las basuras», se convirtió en un verdadero quebradero de cabeza para el Ayuntamiento en el primer tercio del siglo XX.

El vertido de los residuos, sin tratamiento alguno, había sido el sistema empleado tradicionalmente en las ciudades, pero el crecimiento urbano y la industrialización hicieron que al finalizar el siglo XIX el sistema resultara inviable ${ }^{23}$. En Madrid, los escasos, saturados y faltos de acondicionamiento vertederos que rodeaban la ciudad se habían convertido en un problema sanitario, que también afectaba a los municipios colindantes. Las alternativas que se ofrecían, como la construcción de grandes plantas de transformación o incineración, requerían importantes inversiones, que fueron demorándose mientras se realizaban viajes de estudio de los técnicos municipales y proseguían las denuncias en la prensa contra el deficiente servicio. Al comenzar el siglo Xx, el servicio municipal de limpiezas de Madrid no respondía, según manifestaba en 1906 el director del mismo, ni «en su organización ni acaso en ninguno de sus detalles a las reglas que la higiene y la ciencia aconseja» ${ }^{24}$.

Hasta entonces el Ayuntamiento había delegado el servicio de limpieza en un contratista que empleaba poco y pésimo material, con deficientes instalaciones y escaso personal. La creciente preocupación por las condiciones sanitarias y de salubridad hicieron que el Gobierno acusara al Ayuntamiento de incuria y negligencia por su falta de supervisión y control $^{25}$. La celebración de los Congresos nacionales e internacionales de

23 Novo López, 2002.

${ }^{24}$ Chicote, 1906, p. 3 . Un informe municipal fechado en 1895 denunciaba que era «una capital descuidada, cuya limpieza deja mucho que desear [...] donde las reglas de la policía urbana yacen en el más lamentable olvido». AVM, Secretaría, Expediente 18272-3.

25 Dato, 1892; Madrid Moreno, 1899. Madrid Moreno era director del Laboratorio Micrográfico municipal. 
Higiene, y los avances en el campo de la ingeniería sanitaria, colocaron en primer plano la estrecha relación entre salubridad y limpieza pública. En 1895 se adjudicó el contrato del servicio de Limpiezas municipal a una sociedad belga, que introdujo en Madrid algunos avances y mejoras, como el uso de barrederas mecánicas y la instalación de hornos crematorios para incinerar las inmundicias de Madrid ${ }^{26}$, sistema que se había difundido por gran parte de Europa y Estados Unidos desde finales del siglo $\mathrm{XIX}^{27}$, proyecto que fracasó a finales de 1897, ante lo que el Ayuntamiento procedió a la incautación del servicio y material de la sociedad concesionaria ${ }^{28}$. Las acciones administrativas y judiciales desvelaron corruptelas y prevaricaciones en la adjudicación de los contratos ${ }^{29}$, que fueron calificadas como el «timo de los perdigones» ${ }^{30}$. El Ayuntamiento no fue capaz de mejorar el servicio ${ }^{31}$. En 1906 el médico higienista César Chicote, tras ser nombrado Jefe del Servicio de Limpiezas y elaborar una Memoria sobre el mismo, dimitió tras llegar al convencimiento «de que nada podía realizar para mejorarle [...] [al contar con] material escasísimo, deficiente y en deplorable situación» ${ }^{32}$. Todavía estaban en uso, para la recogida de las basuras domiciliarias, los denominados «carros de campanilla» para avisar de su paso a los vecinos, implantados en época de Carlos III. El personal era escaso, 856 empleados - la mayoría operarios dedicados al barrido y riego de calles y transporte de las inmundicias - , que según Chicote no tenía ni la instrucción ni las condiciones físicas requeridas para realizar el trabajo, la mayoría presentaba un aspecto «sucio y astroso [...] nadie creería se trata de ejecutores de un servicio municipal de higiene urbana». Se carecía igualmente de locales adecuados, como talleres y almacenes ${ }^{33}$.

Las necesidades del servicio de Limpiezas municipal estaban claras, existían también los planes para afrontarlas, trazados por los concejales,

26 Ayuntamiento de Madrid, 1895.

27 Gallego, 1907; Chicote, 1897; Tucker, 1977. Véase también Melosi, 2000, pp. 174204, y Clark, 2007.

${ }_{28}$ Expediente instruido a virtud del acuerdo del Excmo. Ayuntamiento de Madrid ... sobre que se proceda a la incautación del servicio de limpiezas..., 1897.

29 Declaración prestada ante la Audiencia de Madrid por Don Luis Felipe Aguilera en el juicio oral celebrado..., 1897.

${ }^{30}$ El Imparcial, 11 de diciembre de 1897.

31 El censo de 1897 registró 512.150 habitantes en Madrid.

32 Chicote, 1921.

33 Chicote, 1906. 
ingenieros y técnicos municipales, pero éstos se estrellaban una y otra vez con la escasez de recursos del Consistorio. Las bases para iniciar su modernización se pusieron a partir de 1914, cuando el Ayuntamiento destinó 1 millón de pesetas para acometer la reorganización del servicio. Aunque insuficiente, se reorganizó y aumentó la plantilla, se adquirieron uniformes adecuados, primer paso para dignificar el trabajo de unos empleados mal pagados ${ }^{34}$, se adquirió ganado y material, incluyendo modernas máquinas automóviles para el barrido y riego de las calles, y se construyó un gran parque central en el sur de la ciudad y uno de zona en el centro ${ }^{35}$. Un nuevo crédito de 4,5 millones de pesetas en 1920 sirvió para proseguir las mejoras - particularmente en el capítulo de la renovación y actualización del material empleado-, aunque resultó insuficiente para una ciudad en acelerado crecimiento ${ }^{36}$. La partida anual destinada al ramo en el presupuesto municipal sobrepasó en 1924 los 5 millones de pesetas, la mayoría se destinaba al pago de los sueldos y jornales del personal -1.500 trabajadores entre fijos y eventuales-, compra y mantenimiento de material y ganado $^{37}$.

La mejora de los pavimentos, la desaparición de las caballerías por la electrificación de los tranvías y la llegada de los automóviles, y la introducción de maquinaria para el barrido y riego, hicieron que la limpieza de las vías públicas, que tanto preocupaba a las autoridades al comenzar el siglo pasara a un segundo plano. En los años veinte el tratamiento del creciente volumen de basuras adquirió un mayor protagonismo. El aumento del bienestar material de la población durante el primer tercio del siglo $\mathrm{Xx}$, se reflejó en la reducción de las tasas de mortalidad y en el incremento de los desechos que producía la población.

La ciudad, que se encaminaba al millón de habitantes al finalizar la década de los veinte, generaba entre 500 y 600 toneladas diarias de basura, un volumen que había que recoger y $\operatorname{tratar}^{38}$. Una parte de los desechos era adquirida por agricultores de la provincia, que los empleaban

${ }^{34}$ El jornal medio de los operarios del Servicio de Limpiezas municipal era de 2,75 pesetas. Arenas Ramos, 1914.

35 Arenas Ramos, 1918.

36 Informe del Jefe del Servicio, César Chicote, fecha 31 de mayo de 1921. AVM, Secretaría, Expediente 29-376-8; Rogelio Sol, 1924.

37 «Como se organiza el servicio de Limpiezas» [entrevista con Rogelio Sol, director del servicio municipal de Limpiezas], El Imparcial, 16 de agosto de 1924.

${ }^{38}$ García Iniesta, 1928. 
como abono; otra gran parte era trasladada por los traperos hasta los pueblos colindantes a Madrid donde residían, debido al sistema de recogida mixto, en el que intervenía el servicio de Limpiezas y cientos de trape$\operatorname{ros}^{39}$. Los camiones y carros municipales recolectaban la basura procedente de las calles, de los establecimientos industriales y de aproximadamente la mitad de los domicilios de Madrid, encargándose los traperos de recoger puerta a puerta lo desechado por la otra $\operatorname{mitad}^{40}$. El amontonamiento de basuras, sin ningún tipo de tratamiento en los alrededores de la capital, era visto en los años veinte como un grave riesgo sanitario, sobre el que alertaron repetidamente los técnicos sanitarios.

En el Congreso Nacional Municipalista de 1925 celebrado en Madrid se aprobó, entre las conclusiones de los debates sobre los servicios de recogida y traslado de las basuras, la necesidad de que en un radio de $5 \mathrm{~km}$ no se permitiera el depósito de basuras, con el objetivo de destruir los estercoleros y cinturones de detritus que muchas ciudades padecían ${ }^{41}$. Las quejas de los vecinos y las denuncias de la prensa y de los técnicos municipales contra el gran vertedero del Este de Madrid, situado junto a la Necrópolis, donde periódicamente se daban plagas de ratas y moscas hicieron mella en el Consistorio.

En 1930, el Ayuntamiento convocó un concurso público para adjudicar el tratamiento de los desechos de Madrid ${ }^{42}$. Un año después, la comisión encargada de juzgar las proposiciones recibidas decidió la adjudicación a dos empresas y sistemas distintos para tratar los residuos urbanos: incineración y fermentación. El tratamiento por el sistema de fermentación fue adjudicado a la S. A. Metgzer, que traspasó sus derechos a la Compañía Madrileña de Mejoras Urbanas. Esta sociedad construyó una planta de tratamiento en el sur de la ciudad, en una zona poco urbanizada

${ }^{39}$ Las familias traperas residían en poblaciones como Chamartín de la Rosa, La Elipa, Vallecas, Fuencarral, Canillejas y Villaverde. En Canillas, los traperos y sus familias llegaban a representar hasta una tercera parte de su población. Escrito del alcalde de Canillas interesando anulación del acuerdo sobre el ejercicio de la industria de recogida de basuras domiciliarias, 1935. AVM, Secretaría, Expediente 29-377-76.

${ }^{40}$ Las licencias se renovaban anualmente, en ellas se especificaba las casas asignadas a cada trapero o trapera. En 1934 el número de licencias renovadas ascendió a 1.123. AVM, Secretaría, Expediente 29-377-41. No obstante, un número indeterminado de traperos trabajaba sin licencia, según reconocía el propio Ayuntamiento.

41 Congreso Nacional Municipalista, Madrid, octubre de 1925, 1925.

42 Gaceta de Madrid de 18 de enero de 1930, Boletín Oficial del Ayuntamiento de Madrid, 20 de enero de 1930. 
junto a la plaza de Legazpi, que comenzó a funcionar a finales de 1934. La fábrica era un gran complejo que empleaba a más de 100 trabajadores, con almacenes, depósitos, talleres, salas de clasificación y selección de la basura, lavaderos, hornos, y las cámaras de fermentación ${ }^{43}$. Estaba diseñada para tratar 73.000 toneladas de basura al año, para su conversión en abono orgánico ${ }^{44}$. Aunque la fábrica de fermentación suponía una mejora considerable, la realidad fue que sólo recibía 200 toneladas diarias de basura, algo menos de la mitad de las que producía diariamente la ciudad en esos momentos.

Mientras, se retrasó la construcción de la fábrica de incineración, tras los problemas surgidos con la Compañía Peninsular de Servicios Públicos, a quien le habían sido traspasados los derechos de adjudicación del servicio $^{45}$. La concurrencia de los traperos parecía inevitable, su existencia y la forma en la que realizaban su trabajo, «del modo primitivo que conocemos, en las barriadas de Cuatro Caminos, Bellas Vistas, Tetuán, Chamartín, La Elipa, Puente de Vallecas, los Carabancheles, etc., es una amenaza constante para la salud del vecindario Su anacronismo representa un atentado a la civilización ${ }^{46}$.

Al finalizar 1935, el Ayuntamiento adoptó las primeras medidas para prescindir del trabajo de los traperos. Se aprobó su retirada, que se realizaría de forma gradual, se prohibió ejercer la actividad sin la preceptiva licencia, y dejaron de concederse nuevos permisos y autorizaciones de traspaso ${ }^{47}$. Se anunció un concurso para adjudicar por contrato la recogida de basuras domiciliarias - la recogida de basuras procedentes de talleres, fábricas y similares las seguiría realizando el servicio municipal-, que al resultar desierto fue convocado de nuevo a comienzos de 1936.

En plena Guerra Civil un informe del Negociodo de Policía Urbana del Ayuntamiento, fechado en julio de 1937, revelaba que se habían vuelto a conceder licencias a los traperos, porque las circunstancias del momento imponían «soluciones transitorias acomodadas a ellas», a pesar

43 ABC, 18 de enero de 1935; Heraldo de Madrid, 17 de enero de 1935.

${ }_{44} \mathrm{El}$ abono obtenido por fermentación se calculó en 60.000 toneladas anuales, que se vendían a 14 pesetas la tonelada, un $8 \%$ era para el Ayuntamiento. Ingeniería y arquitectura sanitarias, 2, febrero de 1935, pp. 5-7.

45 El traspaso de derechos fue aprobado por el Ayuntamiento en 1934. El contrato fue rescindido en 1935, tras los reiterados incumplimientos. La Libertad, 18 de agosto de 1934; El Siglo Futuro, 9 de mayo de 1935.

${ }^{46} \mathrm{Luz}, 12$ de octubre de 1933.

47 AVM, Secretaría, Expediente 29-377-64. 
de que «el Ayuntamiento tiene acordado no expedir nuevas licencias [...] y se pensaba llegar a la supresión de los traperos» ${ }^{48}$. Planes que, como tantos otros, se vieron frustrados a causa de la Guerra Civil y la dura posguerra franquista.

\section{La electricidad y la vida moderna}

La aparición del transformador de corriente alterna y el transporte de la energía eléctrica de alta tensión a grandes distancias permitió la producción de energía hidroeléctrica, mediante la construcción de centrales y presas en el curso de los ríos. La producción hidroeléctrica compitió con creciente ventaja frente a la generación de electricidad por centrales térmicas, basadas en el carbón, y posibilitó el desarrollo del sector eléctrico, mediante la constitución de grandes compañías de producción, transporte y distribución se hicieron con el control del mercado de forma oligopolista durante el primer tercio del siglo XX.

En España, la generación de energía eléctrica de procedencia hidráulica se convirtió en la opción dominante, frente a la de origen térmico. La concentración de la industria en Cataluña y Vizcaya hizo que el despegue del mercado eléctrico estuviera estrechamente vinculado al desarrollo de la sociedad urbana. El alumbrado público y el transporte urbano - el tranvía y el Metro, en Madrid 1919 y en Barcelona 1924- fueron los impulsores de la primera expansión de las redes eléctricas, pronto acompañadas del consumo con fines industriales, empresariales, comerciales y domésticos ${ }^{49}$. El abaratamiento de las tarifas, los conciertos con los poderes públicos - en especial con los ayuntamientos para el alumbrado público-, con las empresas de transporte y los grandes consumidores -empresas e industrias - favorecieron la constitución de las grandes empresas eléctricas, que desde el primer tercio del siglo XX monopolizaron el mercado eléctrico español, en estrecha alianza con el sistema bancario que por entonces se constituyó ${ }^{50}$.

A la altura de 1914 las principales ciudades españolas eran abastecidas por centrales hidroeléctricas con potencias instaladas de $5.000 \mathrm{kw}$. El cambio de la producción eléctrica de centrales térmicas a hidráulicas fa-

\footnotetext{
48 AVM, Secretaría, Expediente 29-377-111.

49 Arroyo Huguet, 2013; Urteaga, 2013.

50 Bartolomé Rodríguez, 2007, pp. 103-107.
} 
voreció el desplazamiento del alumbrado público desde el gas a la electricidad. El encarecimiento del carbón y el abaratamiento de la energía eléctrica, con la entrada en funcionamiento de las centrales hidroeléctricas, facilitó la transición de un sistema de iluminación a otro. Entre 1926 y 1936 la generación de energía de origen hidroeléctrico creció un 57\%, mientras la de origen termoeléctrico - basada en el carbón - lo hizo en cerca del $40 \%$, con el $30 \%$ de la capacidad total de generación ${ }^{51}$. Al iniciarse el siglo 52 empresas producían 66 millones de $\mathrm{m}^{3}$ de gas, que daban servicio a 70 localidades -63 con contratos de alumbrado público-, en 1920 las empresas se habían reducido a 30, la producción a 51 millones de $\mathrm{m}^{3}$ y 33 los municipios con alumbrado público por gas, que a principios de los años treinta disminuyó a 23 localidades (tabla 2) ) $^{52}$.

\section{Tabla 2}

Potencia disponible y producción en España, 1890-1936

\begin{tabular}{rrrrrrrrr}
\hline Año & $\begin{array}{r}\text { Potencia } \\
\text { hidráulica }\end{array}$ & $\begin{array}{c}\text { Potencia } \\
\text { térmica }\end{array}$ & Total KW & $\begin{array}{c}\text { Total } \\
\text { MW }\end{array}$ & $\begin{array}{c}\text { Producción } \\
\text { hidráulica }\end{array}$ & $\begin{array}{c}\text { Producción } \\
\text { térmica }\end{array}$ & Total KWH & $\begin{array}{r}\text { Total } \\
\text { GWH }\end{array}$ \\
\hline 1890 & 3.721 & 9.011 & 12.732 & 13 & 5.581 .688 & 13.516 .312 & 19.098 .000 & 19 \\
1900 & 25.126 & 46.292 & 71.418 & 71 & 37.689 .600 & 69.438 .000 & 107.127 .600 & 107 \\
1910 & 118.498 & 53.782 & 172.280 & 172 & 236.995 .440 & 53.782 .000 & 290.777 .440 & 291 \\
1920 & 509.338 & 151.886 & 661.224 & 661 & 1.018 .675 .956 & 151.886 .286 & 1.170 .562 .243 & 1.171 \\
1930 & 901.511 & 306.996 & 1.208 .506 & 1.209 & 2.883 .932 .249 & 269.849 .356 & 3.153 .781 .606 & 3.154 \\
1936 & 1.249 .817 & 369.479 & 1.619 .295 & 1.619 & 3.365 .756 .319 & 279.325 .368 & 3.645 .081 .687 & 3.645 \\
\hline
\end{tabular}

Fuente: Isabel Bartolomé Rodríguez, La industria eléctrica en España (1890-1936), Estudios de Historia económica, n. ${ }^{\circ}$ 50, Banco de España, Madrid, 2007, p. 131. 1 MW = $1.000 \mathrm{KW} ; 1 \mathrm{GWh}=1$ millón de KWh.

El mapa eléctrico español se configuró sobre la base de las grandes cuencas hidrográficas, que articularon el territorio para abastecer a los centros urbanos de la Península. Madrid con las cuencas del río Alberche, el alto Tajo y el Júcar; Barcelona con las cuencas de los ríos del Pirineo oriental y con el eje Segre-Ebro; Bilbao con el alto Ebro y la cuenca can-

51 Ibidem, pp. 71-95.

${ }^{52}$ Fernández-Paradas, 2009, p. 125. Bartolomé Rodríguez; Fernández-Paradas, y Mirás Araujo (eds.), 2017. 
tábrica y pirenaica occidental, Sevilla con el Guadalquivir, Málaga y Granada con los ríos penibéticos ${ }^{53}$. El tendido de líneas de alta tensión en España fue parejo al acaecido en Francia e Italia, la diferencia estribó en la longitud de la red de alta tensión.

El abaratamiento y mantenimiento de las tarifas, debido a la dura competencia entre empresas, favoreció la expansión del consumo para alumbrado y uso doméstico en la sociedad urbana de la época. Las tarifas para alumbrado doméstico se mantuvieron estables entre 1915 y 1935 , en torno a los 0,50-0,60 pesetas corrientes el $\mathrm{kWh}$, lo que facilitó el crecimiento del $41,4 \%$ de la demanda neta de iluminación frente al $20 \%$ del consumo total de electricidad (tablas 3 y 4$)^{54}$. El uso industrial -incluido el destinado a fuerza motriz - cobró a partir de entonces un creciente protagonismo. La importancia que la electricidad había alcanzado en la sociedad española de los años treinta se reflejó en la inversión realizada en el sector eléctrico, que en 1935 acaparó el $20 \%$ del total invertido en sociedades anónimas. El sector bancario desempeñó un papel protagonista en la constitución y consolidación de las grandes compañías eléctricas, una vinculación que se proyectó a lo largo de todo el siglo XX.

\section{Tabla 3}

Consumo de energía eléctrica en España, 1901-1936

\begin{tabular}{r|rrrrr|ccccc}
\hline \multirow{2}{*}{ Año } & \multicolumn{5}{|c|}{ Consumo en Gigawatios/hora GWh } & \multicolumn{5}{c}{ Consumo en \% } \\
\cline { 2 - 11 } & Alumbrado & Tracción & Industria & Pérdidas & Total & Alumbrado & Tracción & Industria & Pérdidas & Total \\
\hline 1901 & 132 & 12 & 21 & 25 & 190 & 69,47 & 6,32 & 11,05 & 13,16 & 100 \\
1910 & 172 & 32 & 70 & 83 & 357 & 48,18 & 8,96 & 19,61 & 23,25 & 100 \\
1920 & 302 & 80 & 391 & 193 & 966 & 31,26 & 8,28 & 40,48 & 19,98 & 100 \\
1930 & 404 & 239 & 1.450 & 516 & 2.609 & 15,48 & 9,16 & 55,58 & 19,78 & 100 \\
1936 & 527 & 218 & 1.346 & 652 & 2.743 & 19,21 & 7,95 & 49,07 & 23,77 & 100 \\
\hline
\end{tabular}

Fuente: Isabel Bartolomé Rodríguez, La industria eléctrica en España (1890-1936), Estudios de Historia económica, n. . 50, Banco de España, Madrid, 2007, p. 133.

53 Alonso Olea, 2012; Arroyo Ilera, 2012, p. 2.

54 Bartolomé Rodríguez, 2007, pp. 97-98. 


\section{Tabla 4}

Consumo de electricidad en España, 1934

\begin{tabular}{lrrr}
\hline \multicolumn{1}{c}{ Zona } & Consumo kWh & Habitantes & $\begin{array}{c}\text { Consumo kWh } \\
\text { por habitante y año }\end{array}$ \\
\hline Cataluña & 1.005 .180 .018 & 2.701 .292 & 372 \\
Vasconavarra & 499.385 .915 & 1.237 .593 & 405 \\
Levante & 448.520 .209 & 1.896 .738 & 235 \\
Andalucía & 365.297 .180 & 4.609 .870 & 80 \\
Madrid & 284.171 .089 & 1.383 .951 & 205 \\
Asturias-Santander & 263.315 .290 & 1.156 .002 & 225 \\
Aragón & 210.532 .200 & 1.031 .550 & 202 \\
Galicia & 85.935 .210 & 2.230 .281 & 39 \\
Castilla la Vieja & 70.215 .325 & 1.984 .103 & 35 \\
Centro & 34.816 .500 & 2.646 .751 & 13 \\
Canarias & 19.435 .250 & 555.128 & 35 \\
\hline
\end{tabular}

Fuente: Esteban Errandonea Larrache, «Redes eléctricas nacionales», Revista de Obras Públicas, 2.687, 1936, p. 75. El elevado consumo de Aragón era debido a la presencia de industria electro-química, que consumía 123 millones de kWh — de los 210,5 millones totales - .

\section{Madrid y la electricidad}

En 1852 tuvo lugar en Madrid la primera manifestación de alumbrado eléctrico con la iluminación del Palacio Real, hubo que esperar hasta 1882 para que viera la luz la primera compañía de suministro eléctrico, la Sociedad Matritense de Electricidad, filial de la barcelonesa Sociedad Española de Electricidad, que desapareció en $1890^{55}$, a la que siguieron desde 1889 la Compañía General Madrileña de Electricidad, de capital francés - el Crédit Mobilier de los Pereire, que controlaban la Compañía del Gas - , y la alemana AEG - que salió del capital en 1894-, y la The Electricity Supply C. ${ }^{\circ}$ for Spain Limited - popularmente conocida como la inglesa -, absorbida por la primera en 1897, amén de toda una serie de pequeñas compañías dedicadas a proporcio-

55 Maluquer de Motes, 1992. 
nar electricidad a empresas y particulares - como la Sociedad de Electricidad del Sur, la Fábrica de Electricidad de la Zarzuela, la Fábrica de la Princesa, la Fábrica de Electricidad de Buenavista, la Fábrica de Electricidad de Castellana, la Sociedad de Electricidad de Chamberí, la Sociedad de Electricidad del Mediodía, hasta superar la decena- ${ }^{56}$. La proliferación de pequeñas compañías eléctricas, cada una con su propia red y distinta tensión, dieron lugar a superposiciones e ineficiencias que encarecieron los costes de explotación y redujeron los exiguos beneficios en el limitado mercado eléctrico madrileño.

A finales de siglo la Sociedad Madrileña abastecía de electricidad al centro de la capital y al barrio de Salamanca, momento en el que surgió la Sociedad Eléctrica de Chamberí, para dar suministro al de Chamberí. En 1900 los mismos inversores constituyeron la Sociedad de Electricidad del Mediodía, para competir con la Sociedad Madrileña de los Pereire, que reaccionó mediante la toma del control de la Compañía Eléctrica de Alumbrado y Fuerza de capital alemán - Schuckert-, constituida para suministrar electricidad a la Sociedad Eléctrica Madrileña de Tracción, concesionaria de varias líneas de tranvías en la zona norte de la capital.

La intensa competencia y el costoso tendido de las redes de suministro provocaron una delicada situación a ambos grupos, hasta que llegaron en 1907 a un acuerdo de cartelización, por el que se repartieron el mercado y acordaron las tarifas. Su ruptura en 1909 fue el reflejo de la rivalidad por el control del incipiente mercado eléctrico madrileño, cuando la Madrileña se hizo con la fábrica de la Zarzuela y la participación en la Central de electricidad de Pacífico ${ }^{57}$. En 1910 la Compañía General Madrileña, la Sociedad Eléctrica de Chamberí y la Sociedad de Electricidad del Mediodía suministraban el 93,6\% del alumbrado eléctrico en Madrid (tabla 5) ${ }^{58}$.

A principios de siglo la competencia del gas como fuente de alumbrado era todavía considerable en las principales ciudades europeas, incluida Madrid. En 1912 el alumbrado público estaba en manos de la Compañía del Gas, por lo que la implantación de la electricidad en las vías públicas era todavía insignificante, sólo había instalados 192 arcos vol-

\footnotetext{
56 Aubanell Jubany, 1992, pp. 143-171.

57 Ibidem, pp. 149-159.

58 Cayón García, 1997, p. 9.
} 
taicos, frente a los 2.013 faroles de gas, los 12.152 faroles de gas con mechero incandescente y los 850 faroles de petróleo ${ }^{59}$. A diferencia del alumbrado público, las compañías de tranvías abrazaron con prontitud la nueva energía, entre 1898 y 1903 la sustitución de la tracción animal por la tracción eléctrica prácticamente había culminado en Madrid ${ }^{60}$.

\section{Tabla 5}

Abonados a las compañías eléctricas en Madrid, 1890-1910

\begin{tabular}{rrccc}
\hline Año & Madrileña & Chamberí & Mediodía & Total \\
\hline 1890 & 70 & - & - & 70 \\
1900 & 19.163 & 7.022 & - & 26.185 \\
1910 & 29.218 & 14.763 & 7.663 & 51.644 \\
\hline
\end{tabular}

Fuente: Francisco Cayón García, «Un análisis del sector eléctrico en Madrid a través de las empresas Hidroeléctrica Española, Electra Madrid y Unión Eléctrica Madrileña (19071936)», Fundación Empresa Pública, Madrid, 1997, documento de trabajo 97/08, Programa de Historia Económica, p. 9.

Una situación que cambio a partir de 1910 con la irrupción de nuevas compañías de producción y suministro con un mayor músculo financiero y técnico, vinculadas a la producción de energía primaria de origen hidráulico, que dieron lugar a dos grupos: el articulado por el Banco de Vizcaya en torno a Hidroeléctrica Española ${ }^{61}$ - fundada en 1907 - ${ }^{62}$ e Hidroeléctrica Ibérica - creada en 1901 - y Electra Madrid, fundada en 1909 por el Banco de Vizcaya y la Casa Aldama y Cía. - impulsora del Banco Central en 1919-; y el representado por la Unión Eléctrica Madrileña, bajo el liderazgo del Banco Urquijo, a los que se añadía Hidráulica de Santillana - la primera en producir electricidad de origen hidráulico en 1902 desde el salto de Navallar en el río Manzanares - ${ }^{63}$, hasta su ab-

59 Fernández Paradas y Rodríguez-Martín, 2017.

60 Aubanell Jubany, 1992, p. 149.

61 Aubanell Jubany, 2000, pp. 153-185; Cayón García, 2002, pp. 301-334.

62 Valdaliso Gago, 2006, pp. 97-129.

63 Hidráulica Santillana construyó tres saltos sobre el río Manzanares, uno en la presa de Santillana, en el término de Manzanares el Real, otro en Navallar, en Colmenar Viejo, y el tercero en el Cerro de la Marmota, en las lindes del Monte de El Pardo, capaces de 
sorción en 1930. En 1913 los dos grupos formaron un cártel eléctrico que controló el sector en Madrid. Hidroeléctrica Española explotaba la producción de los ríos Júcar y Tajo de Hidroeléctrica Ibérica, y la Cooperativa Electra Madrid se dedicada a la distribución de energía entre los usuarios; mientras Unión Eléctrica asumió las tareas de producción, transporte y distribución ${ }^{64}$. La vinculación de la banca con el sector eléctrico fue determinante para ambos sectores, el Banco de Vizcaya con Hidroeléctrica Española, el Banco Urquijo con Unión Eléctrica y, desde los años treinta, el Banco de Bilbao con Saltos del Duero, fueron los protagonistas de esta alianza que se proyectó a lo largo de todo el siglo $\mathrm{xx}^{65}$.

En 1909 se fundó la Cooperativa Eléctrica de Madrid -impulsada por Joaquín Sánchez de Toca desde el Canal de Isabel II en 1907- por el Círculo de la Unión Mercantil, la Asociación de Propietarios, la Cámara Oficial de la Propiedad Urbana y la Federación Gremial y Patronal de Madrid, con el fin de extender la red eléctrica y abaratar los precios, a través del aprovechamiento hidroeléctrico de las aguas del Canal de Isabel II. La firma de un convenio con el Ayuntamiento en abril de 1910 desató las protestas de las tres compañías dominantes - Madrileña, Chamberí y Mediodía - . En paralelo, se había creado Electra de Madrid, perteneciente a Hidroeléctrica Española, que poseía la capacidad de producción hidroeléctrica procedente de los saltos del río Júcar, pero no contaba con una red de distribución propia. Los intereses convergentes de la Cooperativa Eléctrica y de Electra de Madrid dieron lugar a su fusión el 4 de junio de 1910, bajo el nombre de Cooperativa Electra Madrid, a pesar de su nombre no dejaba de ser una filial de Hidroeléctrica Española (HE), dedicada a la distribución de la energía eléctrica producida por ésta.

El 10 de febrero de 1912 se creó la Unión Eléctrica Madrileña (UEM) a partir de la Compañía General Madrileña de Electricidad - conocida como la Madrileña - , la Sociedad de Gasificación Industrial - fundada en 1905 para producir electricidad a partir del carbón de Puertollano- y Salto de Bolarque - fundado en 1907 en Almonacid de Zorita, Guadalajara, cuya central fue inaugurada el 23 de junio de 1910-, las dos últimas en manos

generar una corriente de $15 \mathrm{kw}$; suministraba energía eléctrica a Colmenar Viejo, Fuencarral, El Pardo, Chamartín de la Rosa, San Sebastián de los Reyes, Alcobendas, Pozuelo de Alarcón, al Palacio Real, la Diputación Provincial de Madrid, y a la Sociedad Eléctrica de Chamberí.

64 Cayón García, 1996.

65 Hernández Andreu, 1994; Bartolomé Rodríguez, 1999; Bartolomé Rodríguez, 2007. 
del grupo Urquijo, a principios de 1913 se hizo con la Sociedad de Electricidad del Mediodía, una parte de cuyos activos pasaron a Electra, en función de los acuerdos del cartel establecido entre HE y UEM, a partir de los dos grupos eléctricos formados por UEM-Mediodía y Electra-Chamberí66.

El establecimiento del cartel madrileño entre HE y UEM fue más allá de la producción y distribución de energía eléctrica. En 1921, en unión con la Compañía Madrileña de Alumbrado y Calefacción por Gas, Electra e Hidráulica de Santillana constituyeron Gas Madrid para operar en el mercado del gas, para hacer frente al monopolio del que había disfrutado hasta entonces la Compañía del Gas. En 1930 HE y UEM se hicieron con el control accionarial de Hidráulica de Santillana, y crearon la Compañía Eléctrica Industrial, para hacerse con Hidráulica del Guadarrama, Eléctrica Castellana, la red de Ciudad Lineal, Eléctrica de los Carabancheles y Cooperativa Eléctrica de los Carabancheles, de esta forma el duopolio eléctrico madrileño se hizo con la producción y distribución de la energía eléctrica en la periferia de la capital. En 1936 HE, la UEM y Saltos del Duero firmaron un convenio en el que también participaron Saltos del Alberche, Eléctrica de Castilla, Hidroeléctrica Ibérica y Electra de Viesgo para facilitar la interconexión de sus redes y centrales eléctricas, acuerdo interrumpido por el estallido de la Guerra Civil ${ }^{67}$.

En los años treinta el abastecimiento hidroeléctrico de Madrid abarcaba una extensa región que iba desde el embalse de Santillana en la Sierra de Madrid, con el salto de Navallar - a $25 \mathrm{~km}$ de la capital-, los 60-80 km de Burguillo, con el Salto del Alberche en Ávila, y los más de $300 \mathrm{~km}$ del sistema de la cuenca del Júcar, a partir del salto de El Molinar.

El abaratamiento de las tarifas entre 1903 y 1912 favoreció la expansión de la electricidad en Madrid, incluido el suministro para calefacción, hasta que la cartelización del mercado por parte de HE y UEM estabilizó los precios. El 15 de marzo de 1913 HE y UEM establecieron una tarifa común que se mantuvo hasta la segunda mitad de los años veinte $-0,60$ pesetas el $\mathrm{kWh}$ para alumbrado y 0,25 pesetas el $\mathrm{kWh}$ para uso industrial - . Fruto de la guerra de tarifas la Sociedad de Electricidad de Chamberí se vio obligada a fusionarse con Electra - de HE - en diciembre de 1913, mientras UEM absorbió a Mediodía, Princesa y Espuñes. Algo similar ocurrió en Barcelona con la pugna mantenida entre las

\footnotetext{
${ }^{66}$ Lázaro Urra, 1924; Cayón García, 1996, pp. 17-28; Aubanell Jubany, 1992.

${ }^{67}$ Cayón García, 2002, pp. 228-331.
} 
empresas AEG y Siemens, hasta que en 1913 ambas cedieron el control del mercado eléctrico catalán a La Canadiense. La agresiva política de precios, con el fin de conquistar el mercado, hizo que los precios para el alumbrado doméstico se situaran en 0,20 pesetas el $\mathrm{kWh}$, hasta el punto de que a principios de los años veinte Madrid era una de las ciudades europeas con un mayor consumo per cápita de electricidad, al centrar las estrategias empresariales en el consumo urbano y doméstico por el todavía insuficiente desarrollo industrial de la capital.

\section{Tabla 6}

Abonados a las compañías eléctricas, 1914

\begin{tabular}{|c|c|c|c|c|c|c|}
\hline Ciudad & Habitantes & $\begin{array}{c}\text { Consumo } \\
\mathrm{kWh}\end{array}$ & $\begin{array}{l}\text { Consumo } \\
\text { per cápita }\end{array}$ & $\begin{array}{l}\text { Número de } \\
\text { abonados }\end{array}$ & $\begin{array}{c}\text { Abonados } \\
\text { por } \\
100 \text { hab. }\end{array}$ & $\begin{array}{l}\text { Tarifas de } \\
\text { alumbrado } \\
\text { (ptas./kWh) }\end{array}$ \\
\hline Chicago & 2.391 .000 & 991.741 .000 & 414,78 & $\begin{array}{c}185.000 \\
(1912)\end{array}$ & $\begin{array}{c}8,47 \\
(1912)\end{array}$ & $\begin{array}{c}0,44 \\
(1910)\end{array}$ \\
\hline Berlín & $\begin{array}{c}2.071 .257 \\
(1910)\end{array}$ & $\begin{array}{c}244.000 .000 \\
(1912)\end{array}$ & $\begin{array}{l}117,80 \\
(1912)\end{array}$ & - & - & $\begin{array}{c}0,53 \\
(1909)\end{array}$ \\
\hline Madrid & $\begin{array}{l}615.075 \\
(1915)\end{array}$ & 41.319 .982 & 67,18 & 95.289 & 15,49 & 0,60 \\
\hline París & $\begin{array}{l}2.888 .110 \\
(1911)\end{array}$ & $\begin{array}{c}87.400 .000 \\
(1913)\end{array}$ & $\begin{array}{r}30,26 \\
(1913)\end{array}$ & 146.700 & 5,08 & $\begin{array}{c}0,75 \\
(1910)\end{array}$ \\
\hline Roma & $\begin{array}{l}542.123 \\
(1911)\end{array}$ & $\begin{array}{l}9.691 .060 \\
(1912)\end{array}$ & $\begin{array}{r}17,88 \\
(1912)\end{array}$ & $\begin{array}{c}15.052 \\
(1912)\end{array}$ & $\begin{array}{c}2,78 \\
(1912)\end{array}$ & $\begin{array}{c}0,70 \\
(1910)\end{array}$ \\
\hline
\end{tabular}

Fuente: Anna Maria Aubanell Jubany, «La competencia en la distribución de electricidad de Madrid, 1890-1913», Revista de Historia Industrial, 2, 1992, p. 168.

En 1914 el consumo de electricidad para alumbrado privado era sensiblemente superior a los registrados en París y Roma, el número de abonados por cada cien habitantes superaba a París, Roma y Chicago (tabla 6), hasta el punto de ser la ciudad que había alcanzado un mayor nivel de socialización de la electricidad, por la competencia en la captación de abonados particulares, a través de una agresiva política de precios. El abaratamiento de los precios hizo que el número de abonados llegará a los 95.289 a finales de 1914 - con una tasa de crecimiento anual entre 1909 y 1914 
del 14,9\%- - ${ }^{68}$. En 1936 los abonados a las compañías eléctricas alcanzaron la nada desdeñable cifra de $245.000^{69}$.

Madrid encontró en la electricidad la fuente de energía necesaria para su despegue industrial, industria química, alimentaria y en la fabricación de maquinaria fueron los sectores en los que despuntó con el nuevo siglo $^{70}$. El avance de la segunda ola industrializadora, apoyada en nuevas fuentes de energía y centrada en nuevos sectores productivos, disolvió muchas de las causas que habían impedido la aparición de fábricas en el paisaje madrileño. La presencia de las altas chimeneas de fábrica cuya ausencia se había reprochado a la capital, comparándola con Barcelona y Bilbao, modificó el mercado laboral madrileño, abriendo nuevas oportunidades para los inmigrantes que llegaban a la ciudad. La construcción mantuvo un importante peso en la vida económica madrileña, aunque perdió la absoluta hegemonía en el mercado de trabajo que había desempeñado en la segunda mitad del siglo $\mathrm{XIX}^{71}$.

Con la electricidad se iluminaron las principales avenidas, calles y viviendas con la extensión de la red eléctrica, mientras los nuevos aparatos hacían más llevadera la vida en los hogares. Calefacción, bombillas, teléfonos, radios, neveras, cocinas y todo un sinfín de electrodomésticos comenzaron a llenar las residencias de los sectores urbanos acomodados, e impulsaron los cambios en los modos de vida, usos y costumbres de los habitantes de la capital, a ello coadyuvó el cine y la publicidad con su poder de fascinación y socialización de los nuevos estilos de vida y sistemas de valores. Los nuevos comercios poblaron con sus escaparates iluminados y sus anuncios de neón el centro de la ciudad y aparecieron los primeros grandes almacenes, como los Almacenes Rodríguez en 1922, los Almacenes Simeón en 1923, el Madrid-París se inauguraba en la Gran Vía madrileña en enero de 1924, Sederías Carretas en 1934 por parte de Pepín Fernández, quien fundaría Galerías Preciados en 1943, y Ramón Areces fundaba El Corte Inglés en 1935.

El ritmo de vida de la capital se aceleró, las calles y plazas principales se llenaron de paseantes, curiosos y consumidores atraídos por las luces de neón de los nuevos comercios y espectáculos, ávidos de las no-

68 Aubanell Jubany, 1992, pp. 170-176.

69 Germán de la Mora, 1937, p. 6.

70 García Delgado, 1990 y 1992.

71 Pallol, 2015; Vicente, 2015; Carballo, 2015; Beascoechea y Otero, 2015; De Miguel, 2016; Díaz, 2016. 
vedades que les ofrecía el gran escaparate en el que se había convertido el centro de Madrid. La Gran Vía se pobló con los fascinantes cartelones de los estrenos cinematográficos y las masas irrumpieron en tropel en las oscuras salas para contemplar las nuevas estrellas del firmamento del celuloide ${ }^{72}$.

\section{La creación de una red de transporte y la metropolización de Madrid}

La expansión urbana en Madrid, Barcelona, Valencia y Bilbao durante el primer tercio del siglo Xx rebasó los límites municipales, mediante la incorporación del extrarradio y los pueblos colindantes, dando inicio a su proceso de metropolización, en el que la construcción de una red de transportes integrada, con la combinación de ferrocarril, tranvía, Metro, autobuses y automóviles hizo que dejaran de ser - utilizando la terminología anglosajona - walking city, es decir, ciudades abarcables a pie, para convertirse en traffic city, urbes organizadas sobre la base de extensas redes de transporte público, imprescindibles para garantizar la movilidad interior en sus amplios perímetros metropolitanos ${ }^{73}$.

El tranvía vivió su edad de oro con su electrificación y expansión hasta el extrarradio, hasta superar los 212,4 millones de viajeros anuales en 1933; un medio que sufrió la creciente competencia del ferrocarril metropolitano - el popular Metro - tras su inauguración en 1919 - en 1934 transportó más de 101,5 millones de viajeros-. Los vehículos a motor conquistaron la ciudad en los años veinte, con la consiguiente transformación del espacio urbano, en 1931 circulaban más de 22.000 automóviles, 3.500 taxis y más de 6.000 camiones y motocicletas, a los que se unían los 600 tranvías eléctricos que recorrían las calles de Madrid. Al proclamarse la Segunda República, Madrid se había convertido en una moderna metrópoli que padecía los mismos problemas que el resto de las grandes capitales y ciudades del mundo ${ }^{74}$.

La red de transporte madrileña comenzó a tejerse con las primeras líneas de tranvía en el último tercio del siglo XIX, establecidas para co2018.

72 Otero Carvajal, 2013; Rodríguez Martín, 2015; Otero Carvajal y Pallol Trigueros,

73 Otero Carvajal, 2017.

74 Rodríguez Martín, 2015; De Miguel Salanova, 2016. 
nectar el centro con los nuevos barrios del Ensanche, la primera línea se inauguró en 1871 entre el barrio de Salamanca y el barrio de Pozas. La introducción de los tranvías de tracción animal supuso una primera revolución en el transporte y movimiento de pasajeros en el interior de la urbe. En esos momentos el tranvía se ofreció como un medio de transporte cómodo y económico, con horarios frecuentes y regulados. Al iniciarse el siglo Xx, la red tranviaria de Madrid tenía 23 líneas - tanto de vía ancha como de vía estrecha - y estaba inmersa en el proceso de sustitución de la tracción animal y de vapor por la eléctrica.

La electrificación de los tranvías supuso un gran esfuerzo económico para las distintas compañías concesionarias, la mayoría de ellas de capital belga. En 1920 se constituyó la Sociedad Madrileña de Tranvías - SMT - empresa de capital español que adquirió los títulos de cinco de las seis concesionarias existentes ${ }^{75}$. El tranvía era el medio de transporte más popular en Madrid, accesible a la mayoría de la población, de 79,2 millones de viajeros de 1910 se paso a más de 212,4 millones en $1933^{76}$. El aumento de las necesidades de movilidad de una población cercana a un millón de habitantes, y la estabilidad a lo largo del periodo del precio de los billetes - entre 5 y 50 céntimos según trayecto - , fueron factores decisivos del uso masivo del tranvía en Madrid (tabla 7).

\section{Tabla 7}

Tranvías, Madrid 1910-1933

\begin{tabular}{c|c|c|cc}
\hline & 1910 & 1926 & 1933 Tranvías urbanos e interurbanos \\
\cline { 2 - 5 } & $\begin{array}{c}\text { Viajeros tranvías } \\
\text { eléctricos }\end{array}$ & $\begin{array}{c}\text { Viajeros tranvías } \\
\text { eléctricos }\end{array}$ & Viajeros & $\begin{array}{c}\text { Longitud líneas } \\
(\mathrm{kms})\end{array}$ \\
\hline Madrid & 79.218 .124 & $180.921 .889 *$ & 212.419 .000 & 133 \\
\hline
\end{tabular}

* Los datos corresponden a la Compañía Madrileña de Tranvías para el ejercicio 1925-1926.

Fuente: Enrique de la Torre, Anuario de ferrocarriles y tranvías, 1910-1935.

75 Burgaleta, 1988; Alberich González, 2013.

${ }^{76}$ Memorias de la Sociedad Madrileña de Tranvías, distintos años. 
La popularidad del tranvía no estuvo exenta de problemas, tanto entre los usuarios y la compañía como entre ésta y el Ayuntamiento. Los primeros porque sufrían las deficiencias del servicio, particularmente el incumplimiento de horarios y la falta de vehículos en alguna de las líneas, que daba lugar a la masificación de los coches, con las consiguientes protestas de los pasajeros; y con el Consistorio por ser el encargado de imponer y hacer cumplir los reglamentos a que debía sujetarse la compañía de tranvías. Al comenzar los años veinte, la creciente congestión del tráfico en Madrid llevó a las autoridades locales a plantear la progresiva retirada de los tranvías de la zona central de la ciudad, algo que ya habían comenzado a hacer otras grandes capitales europeas como París y Londres. Sin embargo, los intentos de sustituir los tranvías por trolebuses o autobuses, considerados vehículos más flexibles frente al tranvía, no prosperaron.

Aunque sin rival en el transporte en superficie, el tranvía tuvo un gran competidor en Madrid: el conocido popularmente como Metro, el ferrocarril subterráneo que inauguró el 17 de octubre de 1919 su primera línea Sol-Cuatro Caminos. Se convirtió en la primera población del mundo con menos de un millón de habitantes en contar con Metro. Su éxito fue inmediato, a pesar de las reticencias iniciales que despertó el proyecto $^{77}$. Entre 1919 y 1936 la Compañía del Metropolitano contaba con tres líneas - más el denominado ramal Isabel II-Norte - con una longitud total de $20,6 \mathrm{~km}$, que atravesaban la ciudad de Norte a Sur y de Este a Oeste.

En su primer año de servicio, con una sola línea, el Metro transportó a 14,6 millones de viajeros, en 1930 fueron 90,3 millones y en 1934 101,5 millones (tabla 8). Buena parte del éxito se debió a unas tarifas asequibles para las clases trabajadoras. El precio de los billetes osciló entre los 10 y los 40 céntimos, con tarifas reducidas en determinadas franjas horarias en los billetes de ida y vuelta. El Metro obtenía la energía eléctrica a través de sus centrales convertidoras de Pacífico, Castelló y Olid, suministrada por HE y UEM, en la central de Pacífico disponía además de una central Diesel de reserva de su propiedad; mientras Tranvías de Madrid lo hacía de las centrales de Mazarredo y Gobernador - UEM - y San Bernardo $-\mathrm{HE}-{ }^{78}$.

77 Otamendi, s. f. [¿1944?]; Moya, 1990; VV. AA., 2010. La historia contable de la compañía en Ruiz Zapatero, 2015.

78 Spottorno y Manrique de Lara, 1945. 


\section{Tabla 8}

Pasajeros trasportados y recaudación de la Compañía del Ferrocarril Metropolitano de Madrid, 1920-1936

\begin{tabular}{ccc}
\hline Año & Número de viajeros & Recaudación (en pesetas) \\
\hline 1920 & 14.627 .466 & $2.207 .642,91$ \\
1922 & 30.130 .202 & $30.130 .202,00$ \\
1924 & 42.328 .657 & $7.531 .991,37$ \\
1926 & 67.664 .276 & $10.875 .400,18$ \\
1928 & 70.748 .539 & $12.057 .217,32$ \\
1930 & 90.256 .327 & $15.337 .828,35$ \\
1932 & 99.876 .380 & $16.493 .543,29$ \\
1934 & 101.500 .676 & $17.058 .219,11$ \\
1936 & $(-)$ & $17.058 .219,11$ \\
\hline
\end{tabular}

Fuente: Memorias de la Compañía del Ferrocarril Metropolitano, elaboración propia.

La expansión de los automóviles en los años veinte aumentó exponencialmente el movimiento diario de viajeros en la capital. A los transportes urbanos disponibles - tranvías, Metro, coches de sangre de alquiler-, se sumaron en ese periodo los autobuses, los taxis y las motocicletas de alquiler. Las primeras líneas de autobuses urbanos comenzaron a funcionar en Madrid en 1922, a cargo de la Sociedad General de Autobuses de Madrid - SGAM - , a quien el Ayuntamiento otorgó licencia para explotar el servicio de pasajeros en autobús por el interior de la ciudad, en líneas regulares y especiales, por espacio de 20 años. Aunque las cifras de pasajeros de la SGAM revela el incremento de la demanda de transporte en Madrid, la empresa cesó su actividad en 1926, cuatro años después de su fundación, debido a la guerra de tarifas con la compañía de tranvías ${ }^{79}$.

En los años treinta los autobuses volvieron a circular en Madrid, esta vez por cuenta de la SMT, que en 1933 estableció 10 líneas servidas por modernos vehículos de dos pisos, consolidó así su control del transporte urbano en superficie. Además de las líneas ordinarias, la SMT estableció

${ }^{79}$ La SGAM tuvo que hacer frente además a la sustitución de todo su material móvil el primer año de su existencia, a varias huelgas de su personal y a las demandas entabladas contra ella por Arturo Soria, por competir con las líneas de tranvías de propiedad de la Compañía Madrileña de Urbanización. 
servicios especiales, como los que unían el centro con los dos estadios de fútbol de Madrid. Solo en su primer año de funcionamiento, los autobuses de la SMT, transportaron 4.555 .920 viajeros $^{80}$.

Junto al tranvía, cuyas líneas superaban los límites administrativos de Madrid, conectando la ciudad con núcleos de población contiguos como Fuencarral, Leganés o Canillejas, el autobús contribuyó de forma destacada al proceso de suburbanización. La facilidad con la que podía establecerse una línea, pues solo había que conseguir los permisos necesarios y los vehículos, sin necesidad de las grandes obras e inversiones que requería una nueva línea de tranvía, favoreció la proliferación de rutas suburbanas e interurbanas. La Dirección del Tráfico municipal reconocía en 1933 la existencia de 29 líneas suburbanas ${ }^{81}$, aunque eran muchas más las que funcionaban, debido a las que daban servicio a las colonias y barriadas del extrarradio y de municipios limítrofes (tabla 9) ${ }^{82}$.

\section{Tabla 9}

Sistemas de Transportes urbanos y suburbanos, Madrid 1933

\begin{tabular}{l|rrc}
\hline & \multicolumn{1}{|c}{1933} & 1933 & 1934 \\
\cline { 2 - 4 } & \multicolumn{1}{|c}{ Viajeros } & Líneas (kms) & Empleados \\
\hline Sociedad Madrileña de Tranvías & 203.396 .216 & 122 & 2.913 \\
Compañía Metropolitano de Madrid & 106.621 .471 & 19 & 1.459 \\
Autobuses urbanos & 4.555 .920 & 12 & \\
\hline Total & 314.573 .607 & 153 & \\
\hline
\end{tabular}

Fuente: Enrique de la Torre, Anuario de Ferrocarriles y Tranvías 1935 y para datos de autobuses INE: Anuario Estadístico 1934; Para los viajeros de Madrid Sociedad Madrileña de Tranvías, Memoria que el Consejo de Administración... Ejercicio 1933-34, Samarán y Cía., Madrid, 1934.

La expansión de las redes de transporte público en superficie, y la multiplicación del parque automovilístico en Madrid, unidas al crecimiento de la población y a la existencia de un angosto trazado urbano en

\footnotetext{
80 Sociedad Madrileña de Tranvías, 1934.

81 AVM, Secretaría, Expediente 29-59-14.

82 AVM, Secretaría, Expediente 29-59-38.
} 
la parte central de Madrid, provocó la creciente congestión circulatoria, uno de los fenómenos más característicos de la modernidad urbana, el denominado en la época «problema de la circulación» ${ }^{83}$, que para las autoridades municipales no se reducía a los embotellamientos y al tránsito lento en determinadas horas del día y puntos de la ciudad, preocupadas por el aumento de los accidentes de tráfico, la congestión peatonal y los problemas del transporte urbano. En Madrid y Barcelona los vehículos matriculados pasaron de los cerca de 10.000 vehículos matriculados en 1923 a los más de 45.000 de 1933 (tabla 10).

\section{Tabla 10}

Vehículos matriculados, 1923-1933

\begin{tabular}{lccccccccccc}
\hline Provincia & 1923 & 1924 & 1925 & 1926 & 1927 & 1928 & 1929 & 1930 & 1931 & 1932 & 1933 \\
\hline Madrid & 9.598 & 12.152 & 15.422 & 18.120 & 21.460 & 25.435 & 36.168 & 40.210 & 42.037 & 43.720 & 46.852 \\
Barcelona & - & 12.705 & 16.109 & 19.579 & 23.763 & 27.949 & 41.416 & 46.165 & 48.356 & 50.764 & 54.332 \\
\hline
\end{tabular}

Fuente: INE, Anuario estadístico, 1927 y 1934.

El crecimiento del parque de vehículos a motor obligó a adoptar medidas como la formación de una plantilla de guardias especializados en la organización del tráfico o la instalación, en 1929, de señales semafóricas. En los años treinta la cuestión de la organización del tráfico urbano se había convertido en un asunto municipal de gran importancia en otras grandes ciudades del país, como demuestra el que en enero de 1933 se celebrara en Madrid el Primer Congreso municipal de la Circulación, al que fueron invitados todos los ayuntamientos españoles de más de 20.000 habitantes, fue el primer esfuerzo coordinado a nivel nacional para organizar y unificar las reglas del tráfico urbano ${ }^{84}$.

En Madrid se implementaron y ensayaron las primeras normas y disposiciones que trataban de estimular y favorecer el avance de la tracción mecánica y, a la vez, conciliar el uso del espacio por parte de vehículos y peatones ${ }^{85}$. Se aprobaron reglamentos locales de circulación, se formó a

\footnotetext{
${ }^{83}$ Paz Maroto, 1933; Rodríguez Martín, 2015, pp. 157-208.

${ }^{84}$ Rodríguez Martín, 2017a.

85 Rodríguez-Martín, 2017b.
} 
personal especializado en la gestión del tráfico urbano - los guardias de la circulación - , y se implantó la circulación en sentido único y la circulación giratoria en algunas calles y plazas de la capital, se realizaron campañas educativas y se señalizaron las vías públicas - con señales fijas y luminosas - . Madrid fue la primera ciudad de España que introdujo los semáforos para regular el tráfico. Estas y otras medidas destinadas a controlar, ordenar y agilizar la circulación fueron un síntoma del intenso proceso de modernización que experimentó Madrid en el primer tercio del siglo XX.

El crecimiento de la población urbana registrado por Madrid no hubiera sido posible sin la mejora y expansión de las redes de abastecimiento de agua y alcantarillado, así como del servicio de limpieza y recogida y tratamiento de los residuos sólidos, a los que se unieron las de los sistemas de abastecimiento y control sanitario de los alimentos - a través de la apertura y renovación de los mercados de abastos y el desarrollo del Laboratorio Municipal-. Factores de primer orden que mejoraron las condiciones higiénicas y de salubridad de la capital. Madrid dejó de ser la ciudad de la muerte como fue calificada a finales del siglo XIX. Inmigración en continuo aumento y crecimiento vegetativo al fin positivo se aliaron para multiplicar el número de habitantes de la capital, que duplicó su población en treinta años hasta sobrepasar el millón de habitantes. La llegada del agua corriente a los barrios y hogares, y la recogida de basuras, se produjo de manera desigual en función de los diferentes niveles de renta y equipamiento de los mismos, debido a las altas inversiones requeridas para la extensión de la red de abastecimiento de agua a casas e industrias y al cambio de los sistemas de pago, mediante la progresiva implantación de contadores para regular el consumo y pago del mismo. Un proceso que intensificó la segregación del espacio urbano y social de la capital puesto en marcha con el Ensanche y la renovación del centro urbano, expresado en la construcción de la Gran Vía.

El aumento demográfico exigió la extensión urbana. Madrid se convirtió en una metrópoli por el número de sus habitantes y por su cada vez mayor extensión urbana. Expansión urbana que no hubiera sido posible sin la constitución de una red integrada de transporte, mediante la combinación de tranvías, Metro, autobuses, automóviles, camiones y motocicletas, que permitió el inicio del proceso de metropolización de la capital, 
mediante la integración de facto de los municipios limítrofes, que registraron crecimientos significativos de su población frente a la atonía anterior. Para la constitución de un sistema integrado de transportes fueron imprescindibles dos de las innovaciones vinculadas a la segunda industrialización: la electricidad y el motor de explosión, que hicieron posible la edad de oro del tranvía con su electrificación, la construcción del popular Metro y el inicio de la motorización de la sociedad, con la apertura de numerosas líneas de autobuses urbanos e interurbanos y el crecimiento del parque automovilístico. Al proclamarse la Segunda República, Madrid se había convertido en una moderna metrópoli que padecía los mismos problemas que el resto de las grandes capitales y ciudades del mundo, dejó de ser una walking city, es decir, una ciudad abarcable a pie, para convertirse en una traffic city, una urbe organizada sobre la base de extensas redes de transporte público, imprescindibles para garantizar la movilidad interior en su amplio perímetro metropolitano

La llegada de la electricidad a las calles y a los hogares de Madrid liberó a la sociedad urbana del mundo de las tinieblas. Los cambios tecnológicos, económicos y sociales transformaron la vida urbana. Las calles comenzaron a llenarse de automóviles, comercios y centros de esparcimiento y ocio. Se multiplicó la movilidad por los nuevos medios de transporte público, se iluminaron las principales avenidas, calles y viviendas con la extensión de la red eléctrica, mientras los nuevos aparatos hacían más llevadera la vida en los hogares. Agua corriente, calefacción, bombillas, neveras, cocinas, teléfonos, radios, máquinas de coser y todo un sinfín de nuevos productos comenzaron a llenar las residencias de los sectores urbanos acomodados, y cambiaron los modos de vida, usos y costumbres de los habitantes de la capital.

Expansión, reforma y mejora de las infraestructuras urbanas y constitución de una red integrada de transporte fueron factores de primer orden en el proceso de cambio y transformación de Madrid en una metrópoli moderna a la altura de 1936.

\section{Fuentes}

Archivo de Villa de Madrid (AVM).

Biblioteca Digital Hispánica.

Biblioteca Histórica Municipal (Madrid).

Biblioteca Nacional de España. 
Boletín Oficial del Ayuntamiento de Madrid.

Gaceta de Madrid.

Hemeroteca Municipal de Madrid.

Instituto Nacional de Estadística (INE).

\section{Bibliografía}

Alberich GonZÁlez, Joan, Los tranvías de vapor de la ciudad de Madrid, MAF, Barcelona, 2013.

Alonso OlEa, Eduardo J., «El desarrollo del consumo eléctrico en Vizcaya. La Electra de Bolueta (1895-1908)», Vasconia, 38, 2012, pp. 137-164.

Arenas Ramos, Antonio, Proyecto de reorganización del Servicio de Limpieza pública y domiciliaria, Imprenta Municipal, Madrid, 1914.

ARENAS RAMOS, Antonio, Memoria relativa a las mejoras alcanzadas en los últimos años por el Servicio de Limpiezas, Imprenta Municipal, Madrid, 1918.

Arroyo Huguet, Mercedes, «El alumbrado eléctrico en Barcelona, 1881-1935. Infraestructuras urbanas, iniciativas privadas y limitaciones públicas)», Barcelona quaderns d'història, 19, 2013, pp. 157-178.

Arroyo ILERA, Fernando, «El sistema hidroeléctrico del Júcar y la electrificación madrileña», Simposio Internacional Globalización, innovación y construcción de redes técnicas urbanas en América y Europa, 1890-1930, Universidad de Barcelona, 23-26 de enero de 2012.

Aubanell Jubany, Anna Maria, «La competencia en la distribución de electricidad de Madrid, 1890-1913», Revista de Historia Industrial, 2, 1992, pp. 143-171.

Aubanell Jubany, Anna Maria, «Estrategia empresarial y estrategia financiera de la Sociedad Hidroeléctrica Española, 1907-1935», Revista de Historia Industrial, 17, 2000, pp. 153-185.

Ayuntamiento De Madrid, Pliegos de condiciones facultativas y económico administrativas, para los servicios de limpiezas, riegos, extracción y destrucción de basuras... Imprenta y Litografía Municipal, Madrid, 1895.

Ayuntamiento DE MADRID, Condiciones bajo las cuales se ha concedido a la Sociedad Hidráulica Santillana la exención de derechos para la distribución de aguas..., Madrid, Imprenta Municipal, 1910.

Ayuntamiento De MAdRID, Memoria. Información sobre la ciudad. Año 1929, Madrid, s. f. [i1929?].

BARTOLOMÉ RoDRÍGUEZ, Isabel, «La industria eléctrica española antes de la guerra civil: reconstrucción cuantitativa», Revista de Historia Industrial, 15, 1999, pp.139-159.

BARTOlOMÉ Rodríguez, Isabel, La industria eléctrica en España (1890-1936), Estudios de Historia económica, n. ${ }^{\circ}$ 50, Banco de España, Madrid, 2007. 
BARtolomé Rodríguez, Isabel; Fernández-PARAdAs, Mercedes y MirÁs Araujo, Jesús, (eds.), Globalización, nacionalización y liberación de la industria del gas en la Europa Latina (siglos XIX-XXI), Marcial Pons, Madrid, 2017.

Beascoechea Gangoiti, José María y Otero Carvajal, Luis Enrique (eds.), Las nuevas clases medias urbanas. Transformación y cambio social en España, 1900-1936, Catarata, Madrid, 2015.

Bello Pö̈yusan, Severino, Información del Canal de Isabel II que abastece de agua a Madrid, Diana, s.1. [¿Madrid?], s. f. [¿1929?].

BesteIRo, Julián, «El Canal de Isabel II», La Libertad, 10 de mayo de 1925.

Burgaleta, Agustín, Madrid: 101 años de Tranvías, Empresa Municipal de Transportes, Madrid, 1988.

CANAL DE IsABEL II, Memoria oficial sobre el estado de los diferentes servicios en 31 de diciembre de 1908, Imprenta Municipal, Madrid, 1909.

CArballo Barral, Borja, El Ensanche Este. Salamanca-Retiro 1860-1931. El Madrid burgués, Catarata, Madrid, 2015.

CARreras y TAFunell, 2006.

CAYÓN GARCíA, Francisco, Orígenes y evolución de la energía eléctrica en Madrid, 1878-1936, Tesis doctoral, Universidad Autónoma de Madrid, 1996.

CAYÓN GARCÍA, Francisco, «Un análisis del sector eléctrico en Madrid a través de las empresas Hidroeléctrica Española, Electra Madrid y Unión Eléctrica Madrileña. (1907-1936)», Fundación Empresa Pública, Madrid, 1997.

CAYÓN GARCíA, Francisco, «Hidroeléctrica Española: un análisis de sus primeros años de actividad (1907-1936)», Revista de Historia Económica. XX, 2, 2002, pp. 301-334.

Clark, J.F.M., «The incineration of refuse is beautiful: Torquay and the introduction of municipal refuse destructors», Urban History, 34, 2007, pp. 255-277.

Congreso Nacional Municipalista, Madrid, octubre de 1925, Oviedo, Imp. La Cruz, 1925.

Chicote, César, La destrucción de las inmundicias urbanas por el fuego en Inglaterra, Estados Unidos, Francia y Alemania, Madrid, Librería de Fernando Fé, 1897.

Chicote, César, Reorganización del servicio de la limpieza de Madrid. Informe elevado a la Alcaldía Presidencia, Imprenta y Estereotipia de Ricardo Fé, Madrid, 1906.

Chicote, César, El servicio de limpieza. Memoria que eleva al Excmo. Ayuntamiento de Madrid D. César Chicote, Jaime Ratés, Madrid, 1921.

Compañía del Ferrocarril Metropolitano, Memorias, 1920-1936.

DAto, Eduardo, Memoria de la investigación efectuada en todos los actos, documentos, cuentas y expedientes del Ayuntamiento de Madrid, Ministerio de la Gobernación, Madrid, 1892.

De la MoRA, Germán, 26 años de lucha en la industria eléctrica de Madrid, 1910-1936, El Adelantado de Segovia, Segovia, 1937. 
De Miguel, Santiago, Madrid, sinfonía de una metrópoli europea, 1860-1936, Catarata, Madrid, 2016.

De la TORRE, Enrique, Anuario de ferrocarriles y tranvías, Huelves, Madrid, 1910-1935.

Declaración prestada ante la Audiencia de Madrid por Don Luis Felipe Aguilera en el juicio oral celebrado con motivo del proceso seguido contra dieciocho concejales del Ayuntamiento por la adjudicación del Servicio de Limpiezas, Tipografía de Tomás Minuesa de los Ríos, Madrid, 1897.

DíAz Simón, Luis, Los barrios bajos de Madrid, 1880-1936, Catarata, Madrid, 2016.

Espinosa Romero, Jesús y GonzÁlez Reglero, Juan José (coord.), 1851. La creación del Canal de Isabel II, Fundación del Canal de Isabel II, Madrid, 2001, 2 vols.

Expediente instruido a virtud del acuerdo del Excmo. Ayuntamiento de Madrid, en sesión de 5 de marzo, sobre que se proceda a la incautación del servicio de limpiezas... Imprenta y Litografía Municipal, Madrid,1897.

FERNÁNDEZ-PARADAS, Mercedes, «Empresas y servicio de alumbrado público por gas en España (1842-1935)», TST, 16, diciembre 2009, pp.109-131.

FERnÁndez-PARAdAs, Mercedes y RodríGuez MARTín, Nuria (2017), «El servicio de alumbrado público en Madrid (1900-1935)», en Luis Enrique Otero Carvajal y Rubén Pallol Trigueros (eds.), La sociedad urbana en España, 1900-1936. Redes impulsoras de la modernidad, Catarata, Madrid, 2017, 229-247.

GALlEGo, Eduardo, Ingeniería sanitaria. Tratamiento de las inmundicias sólidas, Antonio Marzo, Madrid, 1907.

GARcía Delgado, José Luis (coord.), Las ciudades en la modernización de España. Los decenios interseculares. VIII Coloquios de Historia Contemporánea de España, Siglo XXI, Madrid, 1992.

García Delgado, José Luis, «La economía de Madrid en el marco de la industrialización española», en Jordi Nadal y Albert Carreras (coords.), Pautas regionales de la industrialización española (siglos XIX y XX), Ariel, Barcelona, 1990, pp. 219-258.

García InIESTA, César, «El servicio de Limpiezas en Madrid», Heraldo de Madrid, 13 de septiembre de 1928.

HERNÁNDEZ ANDREU, Juan, «Orígenes expansión y limitaciones del sector eléctrico en España 1900-1936», en Juan Hernández Andreu y José Luis García Ruiz (comp.), Lecturas de historia empresarial, Civitas, Madrid, 1994, pp.159-193.

LÁZARO URRA, Juan, «El abastecimiento de energía eléctrica a Madrid», Revista de Obras Públicas, 2.396 y 2.398, 1924, pp. 12-13 y 43-46.

Los primeros cien años del Canal de Isabel II, Memoria 1946-1950, Madrid, Ministerio de Obras Públicas, 1954. 
Loza y Collado, Emilio, El servicio del agua en Madrid. Estudiado en su aspecto higiénico-administrativo, Establecimiento tipográfico de A. Marzo, Madrid, 1903.

Madrid Moreno, J., «La higiene de Madrid», La Correspondencia de España, 31 de mayo de 1899.

Maluquer De Motes, Jordi, «Los pioneros de la segunda revolución industrial en España: la Sociedad Española de Electricidad (1881-1894)», Revista de Historia Industrial, 2, 1992, pp. 121-142.

MARTínez Martín, Jesús A. y Otero Carvajal, Luis Enrique, La sociedad urbana en el Madrid contemporáneo, Catarata, Madrid, 2018.

Martínez VÁzQuez de Parga, Rosario, Historia del Canal de Isabel II, Fundación Canal de Isabel II, Madrid, 2001.

MATÉS-BARCO, Juan M., «La conquista del agua en Europa: los modelos de gestión (siglos XIX y XX)», Agua y Territorio, 1, enero-junio 2013, pp. 21-29.

MAtés BARCO, Juan Manuel y Novo López, Pedro A., «Gestionar la ciudad moderna: la provisión de agua en Bilbao y Madrid», en Luis Enrique Otero Carvajal y Rubén Pallol Trigueros (eds.), La sociedad urbana en España, 1900-1936. Redes impulsoras de la modernidad, Catarata, Madrid, 2017, pp. 189-228.

Melosi, Martin V., The Sanitary City. Urban Infrastructure in America from Colonial Times to the Present, The Johns Hopkins University Press, Baltimore, 2000.

MoyA, Aurora, Setenta años de historia: metro de Madrid. 1919-1989, Metro de Madrid, Madrid, 1990.

Novo LóPEz, Pedro A., «El agua potable a domicilio y los residuos urbanos bailan un complejo pas a deux (1850-1930): una reflexión metodológica e historiográfica», Historia Contemporánea, 24, 2002, pp. 281-319.

Otamendi, Miguel, El Ferrocarril Metropolitano de Madrid: años 1917-1944, Compañía Metropolitano de Madrid, Madrid, s. f. [¿1944?]

Otero CARVAJAL, Luis Enrique, «Las ciudades en la España de la Restauración, 1868-1939», en VV. AA., España entre repúblicas 1868-1939. Actas de las VII Jornadas de Castilla-La Mancha sobre investigación en Archivos, ANABAD, Guadalajara, vol. 1, 2007, pp. 27-80.

Otero CARvajal, Luis Enrique, «La irrupción de la Modernidad en la España urbana, Madrid metrópoli europea, 1900-1931», en Miguel Ángel del Arco Blanco, Antonio Ortega Santos y Manuel Martínez Martín (eds.): Ciudad y modernización en España y México, Universidad de Granada, Granada, 2013, pp. 247-292.

Otero Carvajal, Luis Enrique, «De capital a metrópoli, Madrid, 1860-1936. Veinticinco años de historia urbana», en Jesús Agua de la Roza, José Antolín Nieto Sánchez, Álvaro París Martín, Fernando Manuel Sánchez Escobar, y Juan Carlos Zofío Llorente, Veinticinco años después. Avances en la 
Historia Social y Económica de Madrid, Universidad Autonóma de Madrid, Madrid, 2014, pp. 387-420.

Otero Carvajal, Luis Enrique, «La sociedad urbana en España. Redes y flujos que impulsaron la modernidad, 1900-1936», en Luis Enrique Otero Carvajal y Rubén Pallol Trigueros (eds.), La sociedad urbana en España, 1900-1936. Redes impulsoras de la modernidad, Catarata, Madrid, 2017, pp. 25-69.

Otero Carvajal, Luis Enrique y Pallol Trigueros, Rubén (eds.), La sociedad urbana en España, 1900-1936. Redes impulsoras de la modernidad, Catarata, Madrid, 2017.

Otero Carvajal, Luis Enrique y Pallol Trigueros, Rubén (eds.), La ciudad moderna. Sociedad y cultura en España, 1900-1936, Catarata, Madrid, 2018.

Otero Carvajal, Luis Enrique y De Miguel Salanova, Santiago (eds.), La escuela y la despensa. Indicadores de modernidad, España, 1900-1936, Catarata, Madrid, 2018.

Pallol Trigueros, Rubén, El Ensanche Norte. Chamberí 1860-1931. Un Madrid moderno, Catarata, Madrid, 2015.

Pallol Trigueros, Rubén; Vicente Albarrán, Fernando y Hernández Quero, Carlos, «Metropolitización y transformación del espacio urbano y de los rasgos sociales en Madrid entre 1900 y 1936», en Luis Enrique Otero Carvajal y Rubén Pallol Trigueros (eds.), La sociedad urbana en España, 1900-1936. Redes impulsoras de la modernidad, Catarata, Madrid, 2017, pp. 99-131.

Paz Maroto, José, Time is money. El problema de la circulación. Memoria premiada por el excelentísimo Ayuntamiento de Madrid en el concurso celebrado el año 1932, Artes Gráficas Municipales, Madrid, 1933.

Pinto CRespo, Virgilio; Gili Ruiz, Rafael y Velasco Medina, Fernando, Proyecto de investigación Historia del Saneamiento de Madrid, Fundación Canal, Madrid, 2015.

Rodríguez MARTín, Nuria, La capital de un sueño. Madrid en el primer tercio del siglo XX, Centro de Estudios Políticos y Constitucionales, Madrid, 2015.

Rodríguez Martín, Nuria, «La aparición del "problema de la circulación” y los orígenes de la gestión del tráfico urbano en España, 1900-1936», Historia Contemporánea, 55, 2017a, pp. 483-516.

RoDRíGUEZ MARTín, Nuria, «En una población moderna hay que saber andar, Debates en torno a la regulación del tráfico peatonal en Madrid, 1900-1936», Registros, 13, 1, 2017b, pp. 166-179.

Rueda LafFond, José Carlos, El agua en Madrid: datos para la historia del canal de Isabel II, 1851-1930, Fundación Empresa Pública, Madrid, 1994.

RuIZ ZAPATERO, José Luis, La innovación en los transportes urbanos en Madrid: la compañía Metropolitano Alfonso XIII y la contabilidad en el periodo 1919-1935, Tesis doctoral, Universidad de Valladolid, 2015. 
SANZ GARcía, José María, El marqués de Santillana que trajo el agua a Madrid, Separata de Anales del IEM, tomo XXVIII, CSIC, Madrid, 1990.

Sociedad Madrileña de Tranvías, Memoria que el Consejo de Administración... Ejercicio 1933-34, Samarán y Cía., Madrid, 1934.

SOL, Rogelio, «El Servicio de Limpiezas en Madrid», La construcción moderna, 30 de mayo de 1924, pp. 109-111.

SpotTorno Manrique de LARA, Rafael, «El suministro de energía eléctrica en Madrid», Revista de Obras Públicas, 2.757, 1945, pp. 49-54.

TUCKER, D. G., «Refuse destructors and their use for generating electricity: a century of development», Industrial Archaeology Review, 2, 1977, pp. 5-27.

URTEAGA, Luis, «Las empresas eléctricas y la oferta de energía en Barcelona: el ciclo de la termoelectricidad, 1881-1913)», Barcelona quaderns d'història, 19, 2013, pp. 157-178, pp.53-76.

VAldaliso Gago, Jesús María, «Los orígenes de Hidroeléctrica Ibérica, Hidroeléctrica Española y Saltos del Duero», en Gonzalo Anes Álvarez de Castrillón (coord.), Un siglo de luz. Historia empresarial de Iberdrola, Iberdrola, Madrid, 2006, pp. 97-129.

Vicente Albarrán, Fernando, El Ensanche Sur. Arganzuela 1860-1931. Los barrios negros, Catarata, Madrid, 2015.

Villanueva Larraya, Gregoria, Hidráulica Santillana: cien años de historia, Madrid, Guillermo Blázquez, 1995.

Vorms, Charlotte, Bâtisseurs de banlieue à Madrid Le quartier de la Prosperidad (1860-1936), Creaphis, Paris, 2012.

VV.AA., 90 años de metro en Madrid. De Cuatro Caminos a Hospital del Henares, La Librería, Madrid, 2010.

\section{Financiación}

Este texto forma parte de las actividades vinculadas a los proyectos de investigación correspondientes a «La sociedad urbana en la España del primer tercio del siglo XX. Madrid y Bilbao, vanguardia de la modernidad, 1900-1936». Proyecto coordinado, Plan Nacional de I+D. HAR201565134-C2-1-P y HAR2015-65134-C2-2-P (MINECO/FEDER). Ambos autores pertenecen al Grupo de Investigación Complutense Espacio, Sociedad y Cultura en la edad contemporánea. 


\section{Datos de los autores}

Luis Enrique Otero Carvajal. Catedrático de Historia contemporánea. Doctor en Historia por la Universidad Complutense de Madrid en 1988. Premio Extraordinario de Doctorado por la Universidad Complutense de Madrid (1988-1989). Profesor de Historia Contemporánea desde el curso 1989-1990. Profesor visitante de la Universidad de Puerto Rico, recinto de Río Piedras, curso 2007-2008. Vicedecano de la Facultad de Geografía e Historia de la Universidad Complutense de Madrid desde el 1 de febrero de 2006 al 19 de enero de 2010 Decano de la Facultad de Geografía e Historia de la Universidad Complutense de Madrid desde el 19 de enero de 2010 a 16 de enero de 2014, reelegido hasta enero de 2018. Autor de numerosos artículos científicos en revistas indexadas y de capítulos de libros en obras colectivas. Director del Grupo de Investigación Complutense «Espacio, Sociedad y Cultura en la edad contemporánea, antes Historia de Madrid en la edad contemporánea" n. ${ }^{\circ}$ ref.: 941149, creado en 2006. Director de 20 tesis doctorales leídas en la Universidad Complutense de Madrid. Las principales líneas de investigación desarrolladas en los últimos 15 años han sido: historia social de la ciudad, historia de Madrid en la edad contemporánea, historia de la ciencia, historia de la ciencia en la España contemporánea, historia de la Universidad española e historia de las telecomunicaciones.

Nuria Rodríguez-Martín (orcid.org/0000-0003-0179-7392.nuria.rodriguezm@ ehu.eus). Es licenciada en Ciencias de la Información y en Historia, con Premio Extraordinario de Licenciatura, y doctora en Historia por la Universidad Complutense de Madrid. Ha sido investigadora Juan de la Cierva en la Universidad del País Vasco y Lectora de español en la Universidad Paris IV-Sorbonne. Es autora, entre otras publicaciones, de la obra La capital de un sueño. Madrid en el primer tercio del siglo XX (Centro de Estudios Políticos y Constitucionales, 2015), galardonada en los XIX Premios Nacionales de Edición Universitaria como la mejor monografía en el área de Arte y Humanidades (2016). 